\title{
A TYPOLOGICAL INVESTIGATION OF THE Y.B. MANGUNWIJAYA'S URBAN CHURCH
}

\author{
Rudy Trisno ${ }^{1}$, Fermanto Lianto ${ }^{1}$, Denny Husin ${ }^{1}$ \\ ${ }^{1}$ Department of Architecture, Tarumanagara University, Jakarta 11440, INDONESIA \\ *Corresponding author; Email: fermantol@ft.untar.ac.id
}

\begin{abstract}
As the iconic buildings in Yogyakarta, the Mangunwijaya's churches contribute a great influence on the city. His wisdom is not only written in his books, but also has been implemented through his architectural projects, revealing a specific composition of a spiritual language. A qualitative study is used to reveal Mangunwijaya's architectural principles, by using the tracing method to highlight the structural elements of his urban churches. A typological investigation is accompanied by retracing Mangunwijaya's drawing, where its spatial composition and form are emphasized through points and lines. Hence, by eliminating decorative elements, the most fundamental components of the churches can be raised, consisting: 1) The roof as the most dominant element, a volume that suggests the openness of the building; 2) Landscape defines a mutual symbiosis between indoor and outdoor, stimulating communication and gesture; 3) A typological composition that respects a RomanCatholic church's principles while revealing a local identity.
\end{abstract}

Keywords: Church; Spiritual; typology; Y. B. Mangunwijaya; Yogyakarta.

\section{INTRODUCTION}

Discussion of the Catholic spirituality in the city of Yogyakarta is hardly being separated from the iconic works of Mangunwijaya (Mulyono, 2016). The most Mangunwijaya's popular works, namely Sendang Sono and kali Code urban kampung have dominated the architectural researches, while neglecting his smaller scale buildings.

Various researches, projects and writings, regarding Mangunwijaya's have been widely published. They are easily found, and heavily quoted by architects, politicians, social influencers, cultural expertise's, and even humanists; However, only a few researches have been conducted towards typology, as a research method to examine the spiritual aspects of Mangunwijaya's churches. More architectural studies are focused on cultural aspects, tectonic investigation and material expression (Leevianto \& Aly, 2017), rather than revealing the compositional logic of Mangunwijaya's architectural projects.

This study offers a typological review as the state of the art, exploring the compositional logic in contrast to previous researches, by highlighting connectivity between architectural elements and revealing building integration (Kirana, 2018), including the city's environment as the context. Buildings are extracted to reveal its pure form, showing points and lines as the basic design element by utilizing the tracing method to produce the diagram as an auxiliary tool or a wizard.

In order to verify the connections, imaginary lines are indicated to present physical order, fundamental elements and building volume. Through literature and comparison against Mangunwijaya's principles, a new perspective will be raised, accom- panied by physical evidence, found in this research. Although points and lines are understood as the basic element in architecture, the diagram elaborates their function as the instrument of the research. That is why, the diagram in this paper is drawn specifically not only as an illustration, but mainly is created strategically as the evidence to clarify Mangunwijaya's architectural composition. However, to investigate his project comprehensively, his architectural composition shall be read as a code. The code shows a specific pattern and logic that contribute to the spiritual aspects of the building. Only by then, a new interpretation can be constructed based on the science of typology, contributing a new understanding through a connection between buildings and their immediate environment.

In order to address the architectural issue significantly, local and global studies, research and report are linked to construct a new typological understanding. The spiritual typology in this paper does not a concern with the Mangunwijaya's church, but also trying to stimulate innovation while respecting the Roman Catholic church as its proto(type).

\section{MATERIAL AND METHODS}

\section{The Case Study}

The chosen urban church is located in the boundary of Yogyakarta city's. The city respects the Javanese philosophical axis and applied as the Yogyakarta's urban guideline. The Alfonsus de Ligouri and the Albertus Agung church (Figure 1) are designed and planned according to Mangunwijaya principles, and complied with the urban criteria, respecting the tropical architectural idea. 


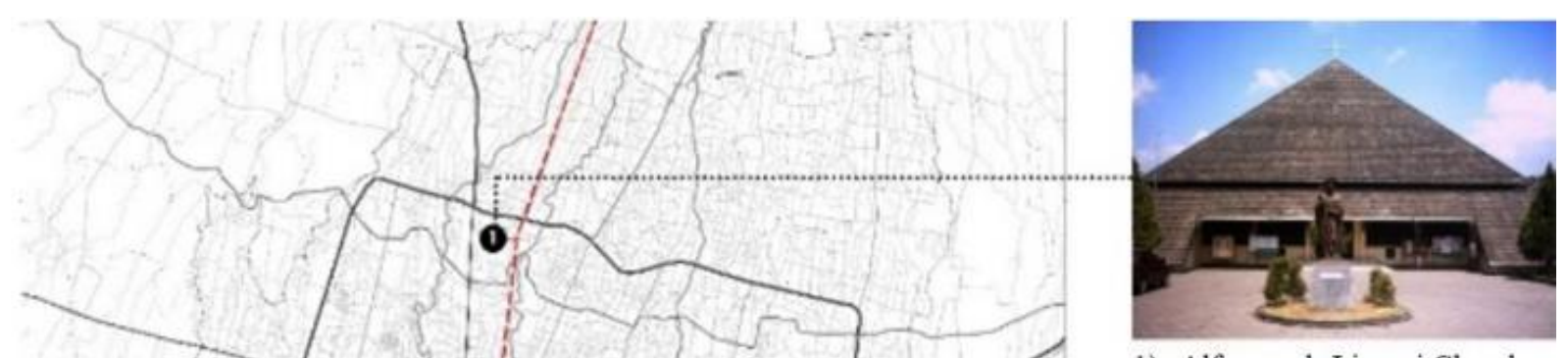

1) Alfonsus de Ligouri Church

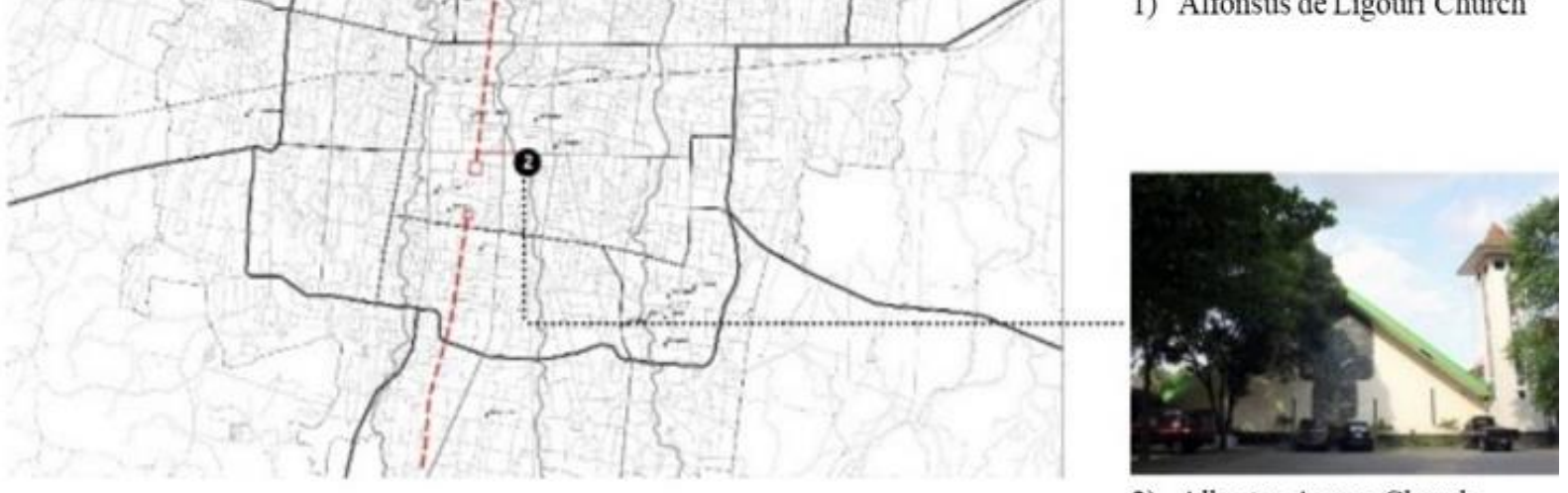

2) Albertus Agung Church

Legend:

1) Alfonsus de Ligouri Church; 2) Albertus Agung Church;

- Javanese Philosophical Axis

Figure 1. The Location and the Photo of the Alfonsus de Ligouri and Albertus Agung Church

\section{METHODOLOGY}

To profoundly investigate the spirituality of the objects, the historical background of the word spirit is helpful to understand the concept. Etymologically, although the word spiritual in general has always been associated with religious aspects, the Medieval Latin word: ecclesiastical initiates a literal meaning as: to breath, breathing, wind or air, an analogy of a living soul to represent the spirit. The idea of spirituality has always been closely adhered to the church, accommodating people with a sense of serenity so that people can find peace. The ancient French word, spirit contributes meaning regarding vital principles of human or animal life, while modern French words mean spirit is translated literally as a spirit or a soul. The soul is believed as a character which represents the living, like: timid, brave or proud, while the body represents the physical material.

While the supernatural is differentiated beyond physical, something that transcends the natural body; the soul is considered as an immaterial being; like angels and demons that symbolize good and bad in the religion (Barrie, 1996). The soul was later described as a natural representation of the body's owner; it is invisible to the naked eye, a substance that is fragile and easily be changed.
Religion distinguishes the holy spirit as the greater substances from the lower ones: ordinary people. Although the concept of spirit may not always be equal to the idea of the soul, the concept of spirit provides the more emotional state that gives significance to the Christian (Eliade, 2002). In addition, it grows a higher understanding regarding the living, in comparison to the previous idea that defines a living thing based on breathing as the indication.

However, to avoid mis-interpretation, this typological review concentrates on spirituality as the idea of a building, this etymology review suggests that humanism is closely related to psychological aspects reflected in the church's spatial composition. As the typology concentrates on the structural elements of the building, the spirituality must be shaped based on the composition of the most fundamental element of the object. An added value may be offered to the typology as a knowledge, as psychology can be related to the building design; For example: human emotion is expressed when an architect designs a building, at the same time design contributes a specific sense of feeling when a visitor experiencing a building (Teh, Lianto, \& Trisno, 2018; Trisno, Hanli, Kasimun, \& Lianto, 2019). That is why, the spatial experience is considered as a fundamental aspect in designing a church. Typology in this sense helps 
describe the qualitative aspects reflected on the spirituality of a building, explaining information like: symbol, direction, experience, perception yet the spatial meanings.

In Indonesia, the church as a genre was inherited by the colonization. The acculturation process has resulted in variation, changes, transformation or even the evolution of the church. A study is required to assist the understanding of the church development process which may be different when compared to the other cultures.

Like the other part of the world, the contemporary development of the Catholic church in Indonesia is highly influenced by the Roman Catholic. The church has been interpreted as the genre that serves Christian society. It is the house of the God, a religious building where worship activities are held. Although, the idea of the church has been modified and developed to specifically accommodate various functions; The concept of the church has never been far away from an idea of a container for people who believe in God. The church is now embracing various backgrounds, strata, hierarchy and features to represent a society that consists of various cultures (Stegers, 2008). A myriad function has been introduced to facilitate distinctive genres and programs like the monastery, chapel, school, university, museum or even commercial although the God has always been claimed as the main purpose.

By understanding the idea of the church, both from global and local perspective, the investigation focuses on the Mangunwijaya's church composition as a forum for fellowship, a container for the congregation. The composition of the building is extracted into its minimum structure to show its most fundamental elements that contribute to form a perception that assists the believer feels closer to the God. That is why, the analysis focuses not only the logic of the church's spatial composition, but also its humanistic approach like emotional and psychological aspects in the building as a strategy for constructing a horizontal and vertical relationships.

In this paper, the church is redrawn as a diagram to show the connection with its context. The diagram presents two- and three-dimensional relationship to its surrounding that contributes a unique spatial experience that is specific for every church. While the plan gives a perception of a two-dimensional plane for showing the horizontal connectivity of the building (Mangunwijaya, 2013), the axonometric composition contributes to volume development and threedimensional connectivity. The diagram is utilized to emphasize the Mangunwijaya's key design and planning, while at the same time it can be interpreted as the language that represents Mangunwijaya's fundamental expression. The interpretation of the diagram considers his background as an architect and a priest, that is strongly related to Roman Catholic principles and humanism reflected in his church as the most ideal building genre that represents his brilliance.

Regarding typology as the study of types, in the field of architecture, the church's composition shall be regarded as the urban element and the city's architecture. As typology is unavoidably related to taxonomy and building classification, elements of the church must be grouped and categorized based on their characteristics (Karen \& Lynda, 1994). The architecture of the church in the context of typology is a type of structure that respects the historical background of the Roman Catholic principles, however as stated before, its transformation process is related closely to the representation of a type of a container, implemented in the tropical architecture concept.

In order to emphasize the Mangunwijaya's most fundamental element of the church, tracing is a typological method that is developed by strategically redrawing the object. It is a method of reducing the actual drawing into the most essential structure, rethinking only the most fundamental elements as the design formula (Unwin, 1997). An architectural diagram is typically redrawn to eliminate the decorative and ornamental elements in order to portray the type's structural components vividly. By reducing the building into its simplest form, a new composition can be reproduced and re-interpreted as a sign. Therefore, through the tracing method, the type can be re-read to its essence. This includes the information regarding the development, hierarchy, replication and even its imitation processes that mimic surrounding nature.

Typology in this paper is intended not only to categorize its structural elements, but primarily to analyses the spiritual aspects of the church. Its spiritual idea is extracted from the development of the form and the compositional formula that concerns about the development of a horizontal and vertical relationship in the building (Trisno \& Lianto, 2018). Through redrawing, re-reading and re-interpreting the composition, a pattern was found, suggesting the connection between human and the spatial quality of the church. In order to assess the spirituality of the church. This research respects the following steps: 1) Tracing Method (diagram making, redrawing by tracing). Diagram filters elaboration in order to emphasize the church's spatial formation, illustrating its structural pattern as the space division and spatial experiences; 2) Points and lines describe its geometric 
shapes, basic foundation of the form including links and networks while showing the bond between internal and external environment; 3) Spatial composition contributes gesture, system, division, and organization including processions that are identical to the activities of the Catholic congregation. Highlights on the diagram are intended to illustrate the patterns, axis, connectivity, accessibility, opening, overlapping planes and elements. The matrix reveals the relationship between ground, landscape and its immediate environment, constructing a virtual understanding while illustrating the architectural transparency.

In this paper, analysis is conducted based on the comparison between architectural diagram, Mangunwijaya's drawing and literature. Scientific explanations are developed by linking spiritual aspect reflected in the spatial composition, compared with other notes, papers, books and previous studies on and done by Mangunwijaya. By combining all the information, a elements. A pattern has emerged from the study of forms and interpreted as the building principles. The argumentation logic and architectural principles can be constructed in relation to the spirituality of the church regarding its urban context. In order to explore beyond typology; Material, relationship, and landscape are also elaborated as the element that supports the building type; Thus, the previous research stagnancy that focused on decoration and ornament can be addressed by offering an alternative: a typological logic of Mangunwijaya's church.

\section{RESULTS AND DISCUSSION}

The Mangunwijaya's churches are commonly designed as a single mass. However, in the later development, the building limitation is often supported by adding a few additional masses. Most of the churches is situated in a closed parcel, equipped by a garden and a limited parking space. These urban churches are located within the city's boundary, surrounded by facilities like housing, commercial, and infrastructure including green area and river. According to Setyoningrum, the Mangunwijaya's church demonstrates a simple tropical architecture. It is a combination of tropical materials, constructed by modern structural elements; while using traditionallymade secondary elements such as doors, ceilings, windows. Ornaments and decorations often adorn their architectural details. Although less fundamental, these details have attracted other researcher's interest, however, typologically this is regarded as only the tertiary elements (Tanuwidjaya, 2013).
In order to contrast other research interest, typology focuses only on the structural expression to find the spirituality of the building. This investigation eliminates tectonics and building styles to answer the stagnancy of general interest in research that more focus on ornamental elements of Mangunwijaya's architecture and art (Tanuwidjaya, 2013). Thus, as a contrast of common researches, this paper highlights a totally different perspective by analysing the Mangunwijaya's church principles rather than focusing on his style.

\section{Tracing Method}

The tracing method is a re-drawing technique, strategically planned to highlight a specific information. It is initiated with planning an illustration with a focus to present a distinctive spatial formation of an object. As a result, a diagram is produced to emphasize only the fundamental elements. This can be achieved by filtering the tertiary elements of the building, thus elimination from any elaborations such as decorations and ornaments generates a minimalistic drawing that demonstrates merely the basic components of the building.

By utilizing tracing methods, a minimum composition of the building can be presented vividly. This description focuses only on the main formation, illustrating clear direction, orientation, location of the building's structure that constructs the overall volume of the building. This method is beneficial in reducing a distraction that often caused by the elaboration both in drawings or when perceiving a building. By interpreting a clear picture, not only easiness can be offered for the perceiver to understand truly the most fundamental building principles, but also logically the perceiver will be only be focused on what is most fundamental. Thus, the typological investigation can be more effective by using a simple diagram as the most fundamental element of the building can be highlighted (Figure 2).

However, in order to present the best result, the diagram must be planned carefully by taking tracing method as the controller. If not planned strategically, only an ordinary sketch will be reproduced as an outcome. Maneuvering the production of the diagram is the key to highlight the structural elements of the building. This method shall be complemented by the strategy of highlighting its basic form in order to differentiate various layers that illustrate the way how: to build, to compose and to organize the buildings through the drawing. Although, the tracing method is helpful in reducing elements that are less important while emphasizing the dominant elements; The 

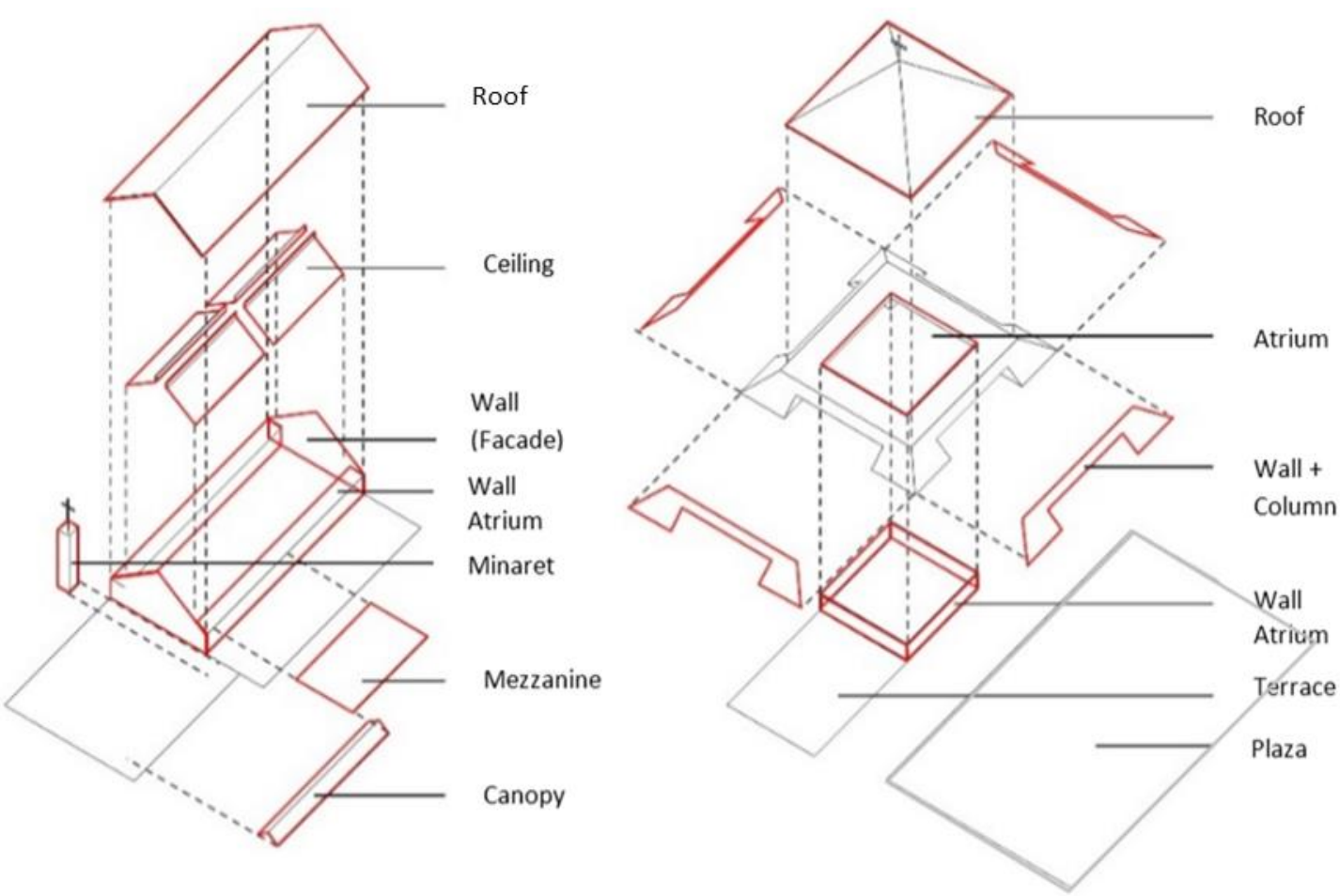

Component and Element of Architecture

Figure 2. Exploded Axonometry. Left: Albertus Agung Church; Right: Alfonsus de Ligouri Church

reduction process must respect the importance of differentiating hierarchy, strata, type of the space so that the diagram can work effectively. That is why colours, line types, shapes, locations, gradation are often used to highlight various components and elements of the building. Specifically, minimum colours and line types are used for highlighting the most fundamental element. In this paper, the grey line is used to indicate the floor, the red line is the main element of the building, the dotted line is the direction of the placement of components. By using a minimum colours and line types, a connection is easily perceived, including emphasizing its basic form as the formula.

Based on the tracing method, it can be seen that there is a psychological influence on the meaning of building ideas that have been experienced in the architect's past (Gervais, 2013). The symbol in Greek is symbollein, which means matching or symbola, which means combining. The logo as a sign or symbol expresses an indirect meaning but can only be recognized by those who study it (Holman, 1986). According to Pierce, the symbol is a sign that shows the natural relationship between the marker with the sign. Relationships are based on community conventions (Zoest, 1993). Symbols of Javanese traditional building forms often dictate Y.B. Mangunwijaya (Trisno \& Lianto, 2020). The meaning of the concept of design based on the tracing method is dominantly originating from the typology of traditional Javanese buildings (Figure 2).

\section{Points And Lines}

Points and lines are the most basic elements of the drawing, they are used to illustrate relationships, revealing the patterns of interconnectedness between the internal and the external environment of the church. The diagram exhibits symbols that are drawn as points and lines so that information given by the drawings can describe: 1) The geometric order, highlighting the idea, the concept, the basic form of the building; 2) Circulation, sequence and procession define the spatial experience of the building. Thus, the diagram can be understood as an information that is presented as a drawing that uses points and lines to highlight the formula of the building.

The Albertus Agung Church has a dominant gable roof. The roof covers the massing block, exhibiting the pitched roof as the triangular shape façade. The roof is developed in a linear manner, and showing a more horizontal characteristic. The overall form of the roof is considered as a triangular prism that corresponds to a linear system that is being introduced in parallel with its inner main circulation. To balance a linear canopy, a bell tower is placed at 
the frontage as a vertical contrast. On the other hand, in term of massing, the Alfonsus de Ligouri church shows an overall polyhedron. Although, one may say it shows a total pyramid. It is not a pure a polygonal base and an apex. An extended diagonal wall has been added to the base as a filter while subtractive parts have been planned to create openings located on the ground. This extended space acts a filter for the visitor, in combination with a symmetrical formation of columns and walls in the internal area of the building. The combination of the two aims to control the distribution of the space by using the sides of the building for entrance while managing the division of the internal space at the same time. As shown in the picture, the basic geometry is emphasized by the solid line, the dash line describes the development of the volume, points show circulation, direction and orientation that correspondence with massing. Hence, while Albertus Agung Church controls one linear distribution of the space by suggesting a singular circulation, Alfonsus de Ligouri church stimulates multi-directionality (Figure 3).
Circulation is planned based on a system of flows that respect the Roman Catholic procession. It dictates a series of sequences and spatial division. The circulation controls how the space will be experienced by the perceiver, offering a specific phasing, defined by a series of spaces. It begins with the entrance and ending at the exit of the church. Although the conventional Catholic procession is held in the internal space of the church, Mangunwijaya offers landscape as an extended space. The axis of the building suggests a connection from the internal area to the outdoors, connecting one building to the other by using the shaded corridor as the transitional space. This information is shown as a solid red line in the drawing, confirming the circulation serves beyond connection as it defines division, organization and orientation of the building. The circulation as indicated in red contributes to the main system of the building. As the grid emerges, the symmetrical formation is revealed to explain the development of both churches. This finding does not only demonstrate the processions that associated with the liturgy, but also
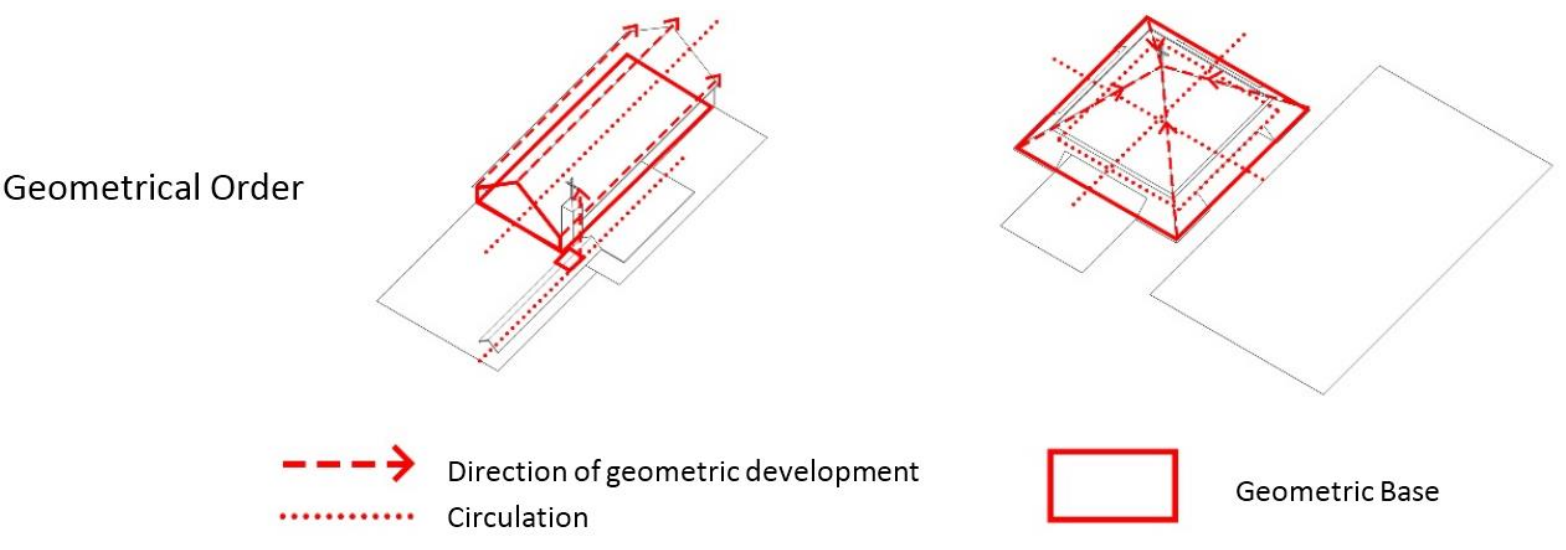

Figure 3. Geometrical Order. Left: Albertus Agung Church; Right: Alfonsus de Ligouri Church

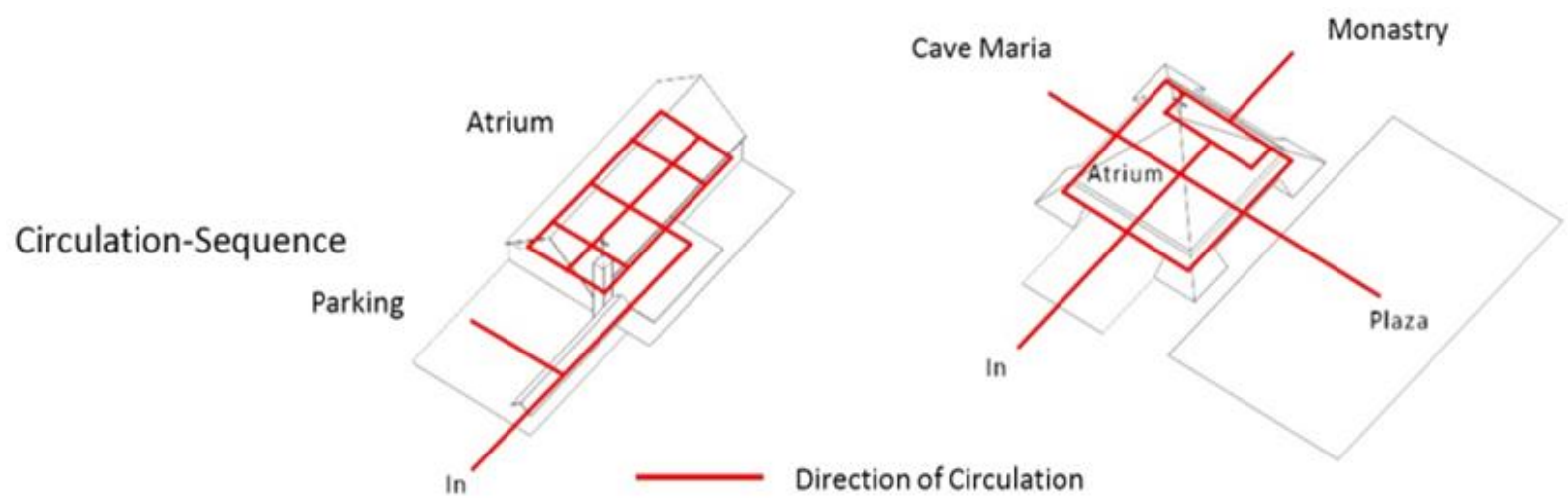

Figure 4. Circulation and Sequence. Left: Albertus Agung Church, right: Alfonsus de Ligouri Church 
determinants of quality of the space, as a spatial system contributes the behaviour control of the visitor, including offering a spatial experience of the church (Figure 4).

\section{Spatial Composition}

Like circulation, spatial composition contributes to gesture, system, division, and organization. As presented on a bigger scale, composition holds the overall form and order of the building rather controlling the flows of the visitor. However, as the composition covers the overall gesture, this contributes area control by using massing as the divider. The composition contributes the arrangement of activity, program, zoning and events in the church that closely related to processions for the Catholic congergation. By drawing planes as the zoning, patterns have emerged, suggesting the arrangement of the space, while transparent layers demonstrate the silhouette of the space while confirming the hierarchy of the space. Rather than designing a church as a single-individual building, Mangunwijaya church's spatial composition demonstrates a collective gesture, as the church establishes an open connection to the

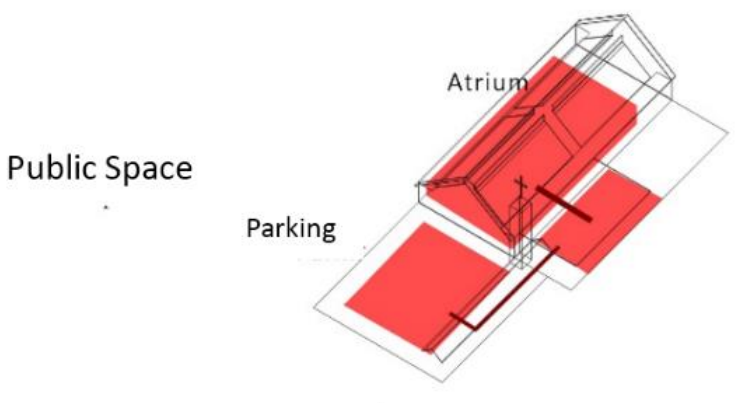

In

Direction of Circulation surrounding environment. The basic form clarifies as a transitional area as a connection and an extended space rather than only an aesthetic garden. Hence, the strength of the composition lies on (Figure 5); 1) The blur distinction between public space and private space, while the garden is used to activate the gaps; division is defined by layers while relationships are strengthened by visual connection between buildings, 2) Size matters, it defines hierarchy, strata, organization and function. Although divided into few massing, physical connection and adjacent location help to define a sense of integration between massing.

Investigation on both churches shows that Mangunwijaya elaborates the same technique: a loosely bounded composition. This composition is potentially interpreted both as to define division, while sharing a connection at the same time. A transitional space is used as a strategy for extending space while bringing nature close to the church. The landscape is a communal garden rather than merely having an aesthetic function. That is why the composition of the mass holds a collection of public and private spaces, utilizing both inside and outside space to stimulate an integration. Direct connection is drawn by a red line to show bonding created by
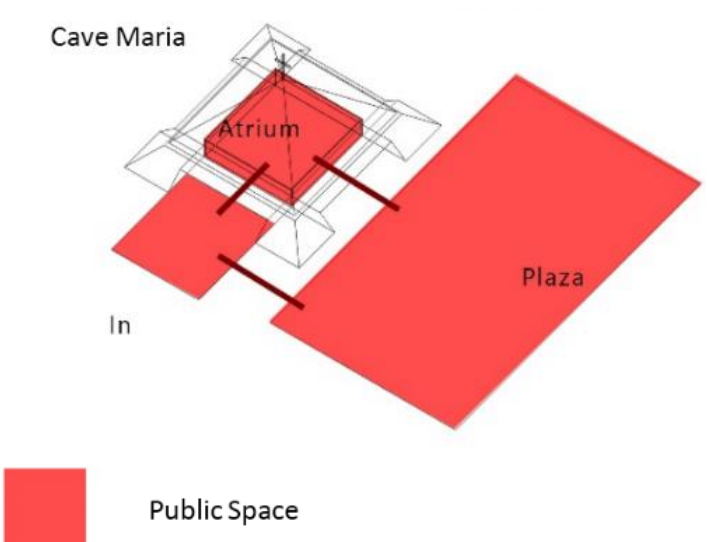

Figure 5. Public, Private and Between Space. Left: Albertus Agung church; Right: Alfonsus de Ligouri church

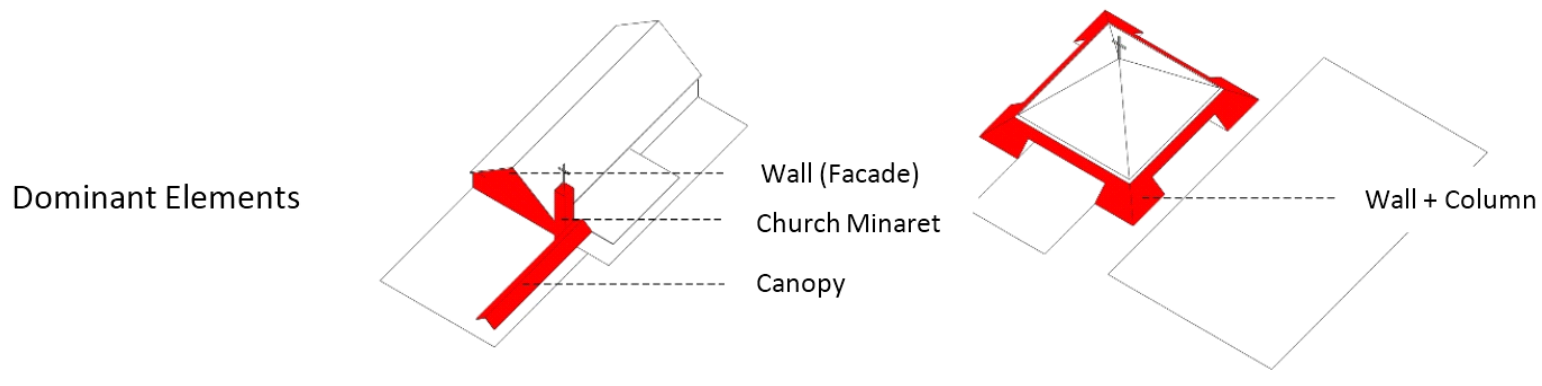

Dominant Element

Figure 6. The Dominant Elements. Left: Albertus Agung church; Right: Alfonsus de Ligouri church 
openings that are facing each other. Outer space acts as a unifier while gaps can be regarded as an extension.

The Albertus Agung church has gaps and open spaces that are intertwined in a continuous manner, starting from the parking lot, terrace and church atrium, while Alfonsus de Ligouri church provides more ample gaps that can be perceived as a garden, a courtyard, a communal space, or a plaza, that located in a middle. Thus, the Albertus Agung creates a quasiextended space by using gaps, while the Alfonsus de Ligouri accommodates a centralized communal space for outdoor connectivity and multi-function forum. Rather than presenting a church in a closed fabric, as shown by the diagrams, Mangunwijaya was interested in presenting the building connection and the outdoor space in relation to architecture. This may contrast the general researches that focus only on the internal organization of the space. This finding reveals that landscape contributes not only as an extended space, a transitional space, an intermediate space, but also as a catalyst that acts like an urban filter so that the church can be presented as more open fabric to the city, accommodating communal space while bringing nature to the architecture as this experience may draw the perceiver feel closer to God by using nature as a medium (Figure 6).

As the majority of Mangunwijaya's projects is easily recognized from its immediate environment, the following explanation explains the usage of the dominant element that contributes a characteristic to the church. The overall form of The Mangunwijaya's church is not only composed by a distinctive feature or most dominant elements of the church, but also presenting at an unusual scale and contrast. Albertus Agung church illustrates the facade wall and the tower bell as the most recognizable elements. The two highlights the entrance of the church, contributing an anomaly to the overall linear form of the massing. On the other hand, the Alfonsus de Ligouri church has the plint as the most dominant element of the massing. The plint supports the roof as one of the most iconic shapes of the building. Although the roof illustrates a dominant feature, the main trick is located on the ground. The plint creates the illusion of the roof size, while playing a role as a filter on the ground. The plint at the base extends the ground floor into a larger area, while acting as a buffer from the surrounding environment.

From the comparison above, although the walls and columns are generally understood as structural elements of the building; Unlike the Western church, the structural element in Mangunwijaya's church does not act as a literal divider or an isolator from the immediate environment. It acts as a filter and a semi-permeable screen that facilitates orientation and invitation while supporting multidirectionality. The relationship between the dominant element of the space with the surrounding environment is vital, as the perception of the audience depends on their immediate environment (Figure 7).

\section{CONCLUSION}

The typology study demonstrates the structural composition of the church as the most fundamental elements in architecture. The diagram shows the pattern of the building, illustrating the overall form of the building and understanding architecture as a series of spaces that correspondents with the surrounding environment. The composition reveals the architectural principles that contribute to its city as the context by utilizing relationship between building and its landscape as a strategy. In relation with the global context, the church indeed possesses strong similarity with the classical Roman Catholic church composition as it is shown by a cross sign found in the overall gesture of the composition, however the overall feature of the building exhibits a totally different architectural idea as inspired by the tropical architecture and influenced by acculturation.

This study contrasts a comparison between Mangunwijaya's church as the local architecture and the global churches as the precedents. The church exhibits a unique characteristic like: 1) The dominant scale of the roof symbolises a tropical idea, this forms a volumetric structure that corresponds with openings that allow natural sunlight to enter the inner space dramatically. The volume demonstrates a gigantic scale as the ambiance and dramatic atmosphere that contributes a religious sense; 2) The base of the building forms a series of columns and walls, forming a specific direction for the procession. The relationship between interior and exterior presents the openness of the building, blurring the boundary between the church and nature; Unavoidably, landscape plays a role as a representation of the God, as nature is believed, bringing the perceiver closer to the God. Exterior provides visual relief as well as extended space and various interpretation towards space, as guided by axis and opening. The exterior can be more easily perceived if we eliminate the style of Mangunwijaya's church by neglecting the elaboration on doors that have drawn more attention in previous research. The ornament and decoration shall be reduced in the typological investigation and categorizing the door as a non-structural element; 3) The investigation suggests a typology contrast between local and global church. Mangunwijaya's design demonstrates an open formation with the roof as the most iconic architectural element while the closed wall mostly dominates the European church while the roof is considered as a minor element.

Therefore, through this research, it can be concluded that the spirituality of the Mangunwijaya's church was not only expressed the emotions as the representation of the soul, but especially towards the open gesture as the suggestion for the surrounding environment. Through its physical composition, Mangunwijaya suggests Catholic society respect Javanese traditional culture, landscape and openness to the city, inviting those from other religion to share wisdom through the open gesture of the Catholic church. Moreover, Mangunwijaya promotes horizontal relationship by promoting communality (between humans and humans) and supporting a dramatic ambiance to stimulate personal growth, nurturing the vertical relationship with the god (between humans and God). 


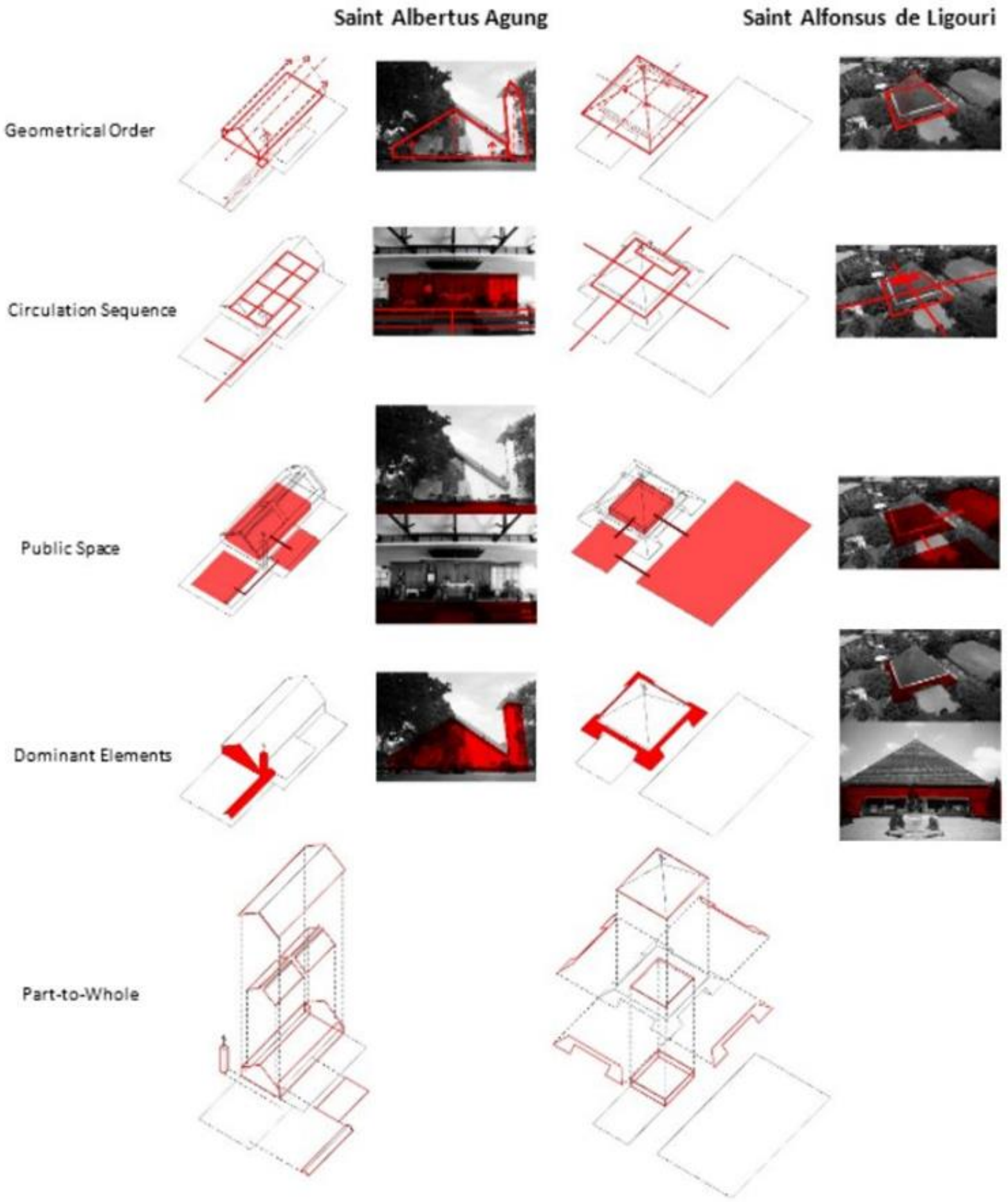

Figure 7. Typological Analysis. Left: Albertus Agung church; Right: Alfonsus de Ligouri church

\section{REFERENCES}

Barrie, T. (1996). Spiritual Path, Sacred Place. Massachusetts: Shambhala Publication.

Eliade, M. (2002). Sakral dan Profan (The Scared and The Profane). Yogyakarta: Fajar Pustaka Baru.
Gervais, W. M. (2013). Perceiving Minds and Gods: How Mind Perception Enables, Constrains, and is Triggered by Belief in Gods. Perspectives on Psychological Science, 8(4), 380-394. Retrieved June 06, 2020. DOI: 10.1177/17456916 13489836, pps.sagepub.com, https://pdfs.seman- 
ticscholar.org/ed14/a2ea65849f4eebde9b66ad23 0a6d3bef67b5.pdf

Holman, C. (1986). A Handbook to Literature (Vol. 5). New York: Macmillan Publishing Company.

Karen, A., \& Lynda, H. (1994). Ordering Space Types in Architecture and Design. New York: Van Nostrand Reinhold.

Kirana, S. M. (2018). Kajian Hubungan Ruang Dalam pada Bangunan Gereja St. Maria Fatima, Sragen, Jawa Tengah. Serat Rupa. Journal of Design, 2(1), 14-25. Retrieved April 13, 2019. https://journal.maranatha.edu/index.php/srjd/arti cle/view/474

Leevianto, J. D., \& Aly, S. (2017). The Architectural Tectonics of Y.B. Mangunwijaya's Design at The Holy Virgin Mary's Cage Complex in

Sendang Sono. Jurnal Riset Arsitektur, 1(2), 83-99. http://journal.unpar.ac.id/index.php/risa/ article/viewFile/2393/2126

Mangunwijaya, Y. (2013). Wastu Citra. Jakarta: Gramedia Pustaka Utama.

Mulyono, A. T. (2016). Program Gereja St. Albertus Agung Jetis dan Gereja Hati Santa Perawan Maria Tak Tercela Kumetiran di Kota

Yogyakarta. Jurnal Multikultural \& Multireligius, 15(1), 144-166. Retrieved April 13, 2019. https://jurnalharmoni.kemenag.go.id/plugins/generic/pdfJsViewer/pdf.js/web/viewer.ht ml?file=https $\% 3 \mathrm{~A} \% 2 \mathrm{~F} \% 2$ Fjurnalharmoni.kem enag.go.id\%2Findex.php\%2Fharmoni\%2Farticl e 2 Fdownload\%2F $210 \% 2 \mathrm{~F} 173 \% 2 \mathrm{~F}$

Stegers, R. (2008). A Design Manual Sacred Buildings. Switzerland: Birkhauser Verlad AG.

Tanuwidjaya, L. (2013). Gaya Desain pada Interior Gereja katolik Santo Albertus Magnus Jetis Yogyakarta. Jurnal Intra, 1(2), 1-7. Retrieved April 13, 2019. http://publication.petra.ac.id/ index.php/desain-interior/article/view/1558/1407
Teh, S., Lianto, F., \& Trisno, R. (2018). The Impact of Column and Beam Construction System to Interior Design Layout According to Fengshui. International Journal of Civil Engineering and Technology, 9(13), 1822-1828. Retrieved April 28, 2019. http://www.iaeme.com/MasterAdmin/ UploadFolder/IJCIET_09_13_182/IJCIET_09_ 13_182.pdf

Trisno, R., \& Lianto, F. (2018). The Meaning of Natural Lighting on Altar Case Study: Cathedral Church and Church of the Light. International Journal of Civil Engineering and Technology, 9(12), 209-213. Retrieved May 02, 2019. http://www.iaeme.com/MasterAdmin/UploadFo lder/IJCIET_09_12_025/IJCIET_09_12_025. pdf

Trisno, R., Hanli, N., Kasimun, P., \& Lianto, F. (2019). The Meaning of Means: Semiology in Architecture Case Study: Villa Savoye. International Journal of Civil Engineering and Technology, 10(2), 653-660. Retrieved May 02, 2019.

http://www.iaeme.com/MasterAdmin/Journal_u ploads/IJCIET/VOLUME_10_ISSUE_2/IJCIE T_10_02_063.pdf

Trisno, R., \& Lianto, F. (2020). Function-Form Relation of Neo-Vernacular Architecture of Salib Suci Church, Jakarta, Indonesia. ISVS ejournal, 7(1), 49-54. Retrieved June 06, 2019. http://isvshome.com/e-journal.html

Unwin, S. (1997). Analysing Architecture. London: Routledge.

Zoest, A. V. (1993). Semiotika tentang tanda, cara kerja dan apa yang kita lakukan dengannya. (Semiotics about the sign, how it works and what we do with it). Jakarta: Yayasan Sumber Agung. 